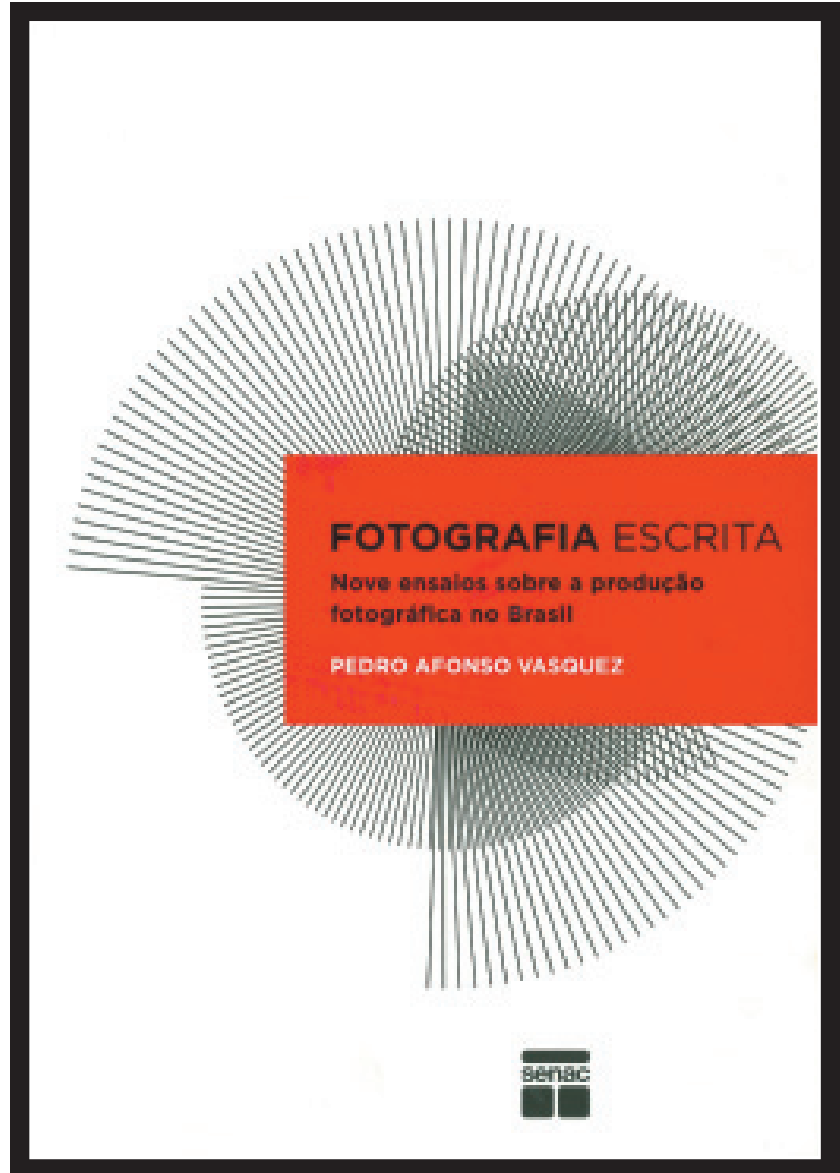

Fotografia escrita: nove ensaios sobre a produção fotográfica no Brasil, de Pedro Afonso Vasquez. Rio de Janeiro, Senac, 2012, 144p. 


\title{
Um ótimo documento fotográfico, sem imagens
}

\author{
A good photographic document, without images
}

\author{
Paulo César Boni*
}

Um dos pesquisadores mais produtivos da fotografia brasileira, o historiador, tradutor e fotógrafo Pedro Afonso Vasquez acaba de iluminar um pouco mais a ainda obscura história da fotografia brasileira com o lançamento do livro Fotografia escrita: nove ensaios sobre a produção fotográfica no Brasil (Editora Senac, Rio de Janeiro, 2012, 144 páginas, $\mathrm{R} \$ 35,00)$.

O livro reúne nove ensaios do autor sobre a trajetória da fotografia no Brasil, de D. Pedro II - considerado o primeiro fotógrafo do país às transformações provocadas pelas tecnologias digitais, no final do século XX e, principalmente, início do século XXI. Os textos, apesar de fragmentos já terem sidos utilizados em aulas, mini-cursos e palestras do autor, são inéditos. E o mais interessante é que, apesar de ser um livro que fala o tempo todo sobre fotografia, não traz nenhuma imagem. Em nota introdutória, a editora lembra que "texto e imagem são aspectos complementares de um mesmo desejo de comunicação" e cita a espirituosa e bem humorada frase de Millôr Fernandes "Se uma imagem vale mais do que mil palavras, então diga isso sem palavras" para justificar que o autor optou por não utilizar imagens justamente para provocar o leitor a pesquisar as cenas sugeridas.

Também em nota introdutória o autor, historiador de primeira grandeza em fotografia, deixa claro suas pretensões com a obra: "Como sempre, procurei debater e não pontificar, entender e não repudiar, ao mesmo tempo me preocupei em olhar para trás apenas para melhor

* Doutor em Ciências da Comunicação pela Escola de Comunicações e Artes da Universidade de São Paulo (ECA/USP). Coordenador do Curso de Especialização em Fotografia: Práxis e Discurso Fotográfico e do Mestrado em Comunicação da Universidade Estadual de Londrina (UEL). E-mail: discursosfoto@uel.br 
vislumbrar o caminho à frente, já que o passado no presente só tem utilidade quando serve de prólogo ao futuro."

O prefácio é do fotógrafo gaúcho Luiz Carlos Felizardo, que lembra ser o autor o fundador da Semana Nacional de Fotografia, quando assumiu o Núcleo de Fotografia da Funarte (Fundação Nacional da Arte), recém-criado por ele próprio em 1982, e enaltece sua importância na pesquisa e recuperação da memória da fotografia no Brasil. O prefaciador, referindo-se aos nove ensaios da obra, encerra enfático seu pronunciamento: "É ler... e pensar. O Pedro se encarrega de fornecer todas as informações e suas reflexões inestimáveis."

Adentrando à obra, o primeiro dos nove ensaios é intitulado Descobertas e reconhecimentos: a família imperial brasileira e a fotografia. Nele, com uma precisão de detalhes inerente aos raros estudiosos da família imperial brasileira, como é seu caso, o autor fala da chegada do daguerreótipo ao Brasil, em 1840. Aproveita para, com base em recente pesquisa da historiadora Maria Inez Turazzi, corrigir alguns erros históricos que estavam se perpetuando pela repetição. Com as devidas correções, o daguerreótipo foi trazido ao Brasil pelo padre (e não abade) Louis Comte (e não Compte), que chegou a bordo do navio Oriental (e não Orientale) e apresentou suas primeiras tomadas de vistas cariocas dia 16 de janeiro de 1840 (e não dia 17).

Neste ensaio, Pedro Vasquez fala da paixão imediata de D. Pedro II pela daguerreotipia, da compra de seu primeiro daguerreótipo - que chegou ao Brasil em abril de 1840 -, do mecenato do imperador pelas artes em geral e pela fotografia em particular e de seu gesto nobre em doar toda sua coleção de documentos à Biblioteca Nacional, imediatamente após sua deposição e banimento do país com a Proclamação da República, sob uma única condição: a de que o conjunto da obra dos documentos doados recebesse o nome de sua esposa. Condição atendida, as mais de 25 imagens tomadas por ele e, principalmente, por mestres nacionais e internacionais da fotografia passaram a compor a Coleção Dona Thereza Cristina Maria. O autor destaca, na página 13, que "para se aquilatar a importância desse 
acervo, basta dizer que foi inscrito pela Unesco no Programa Memória do Mundo".

O segundo ensaio, intitulado Joaquim Insley Pacheco: fotógrafo da Casa Imperial do Brasil e Cavaleiro da Ordem de Cristo de Portugal, traz à tona importantes informações sobre o fotógrafo português Joaquim Insley Pacheco, "um retratista por excelência" como o classifica o autor, na página 31. Pacheco aprendeu o ofício da daguerreotipia com o irlandês Frederick Walter, em Fortaleza, de quem se tornou assistente em 1847. Em 1852 foi para Nova Iorque aperfeiçoar-se no estúdio de Mathew Brady, um dos mais importantes fotógrafos dos Estados Unidos, que se tornaria ainda mais célebre depois da cobertura fotográfica da Guerra de Secessão.

Pedro Vasquez recupera e organiza uma ótima biografia de Joaquim Insley Pacheco, o segundo profissional condecorado como Fotógrafo da Casa Imperial, além de detentor do título de Cavaleiro da Ordem de Cristo de Portugal. O autor informa que Pacheco disputou palmo a palmo com Marc Ferrez o título de o fotógrafo sediado no Brasil que mais participou de exposições nacionais e internacionais. Por fim, destaca, na página 35, que "apesar de ter sido um dos maiores retratistas oitocentistas a atuar no Brasil e, sem dúvida, o mais importante representante de Portugal entre nós, Joaquim Insley Pacheco ainda não recebeu a consagração de um livro dedicado exclusivamente à sua obra". A dica está lançada. Pesquisadores, não se façam de surdos.

George Leuzinger, Marc Ferrez, Juan Gutierrez e Augusto Malta, quatro expoentes da fotografia brasileira - e que fotografaram a cidade de Niterói, onde reside Pedro Vasquez - são o tema do terceiro ensaio: Travessias e fixações: Niterói vista por quatro mestres da fotografia carioca. Nele, o autor narra a trajetória desses fotógrafos pela "terra de Arariboia". O primeiro a fotografar Niterói foi Leuzinger, em 1865, que registrou paisagens que "inspiram os fotógrafos até hoje". O segundo foi Marc Ferrez, aprendiz de Leuzinger, paisagista assumido, com predileção pela fotografia ao ar livre, o que não o impediu de também se tornar um excelente retratista. $\mathrm{O}$ terceiro foi Gutierrez, a quem coube a 
missão de registrar os estragos que os bombardeios da Revolta Armada (1893-1894) impingiram à cidade. O último fotógrafo abordado pelo autor neste ensaio foi Augusto Malta, que, como fotógrafo oficial da Prefeitura da Cidade do Rio de Janeiro, documentou a ampla reforma urbana realizada pelo prefeito Pereira Passos na primeira década do século XX, e fotografou Niterói muitas vezes a serviço. Depois de aposentado, Malta mudou-se para Niterói em 1943 (onde faleceu em 1957), tendo registrado o cotidiano, o humanismo e as paisagens arquitetônicas da cidade.

Apaixonado pela história, Pedro Vasquez dedica os dois próximos ensaios a uma família que fez, pesquisou e preservou a história da fotografia brasileira, os Ferrez. No quarto ensaio Família Ferrez: da escultura à fotografia e do Império à República, fala da saga e da trajetória fotográfica de Marc Ferrez, considerado um dos expoentes da fotografia brasileira de todos os tempos, de seus dois filhos, Júlio e Luciano, e de seu neto Gilberto Ferrez (filho de Júlio). Destaca as características individuais (estilo) de cada um, mas ressalta a importância dos quatro para a preservação da memória cultural, social e arquitetônica do Rio de Janeiro. Na página 63, o autor afirma que: "No campo da fotografia, os irmãos Júlio e Luciano e, mais tarde, o filho de Júlio, Gilberto Ferrez, empenharam-se por conta própria e durante quase meio século em preservar por meio da fotografia as belezas arquitetônicas e urbanísticas da cidade." Mais à frente, na página 66, o autor é enfático: “A fotografia foi para a família Ferrez uma paixão que o velho Marc soube transmitir aos filhos Júlio e Luciano e ao neto, Gilberto, e este às suas sete filhas - responsáveis pela generosa doação do acervo familiar ao Arquivo Nacional. [...] cujo legado felizmente encontra-se hoje à disposição dos pesquisadores e do público em geral."

Gilberto Ferrez, que, inclusive, foi amigo de Pedro Vasquez, mereceu um ensaio à parte Gilberto Ferrez: um dos mais dedicados servidores da fotografia brasileira, no qual o autor destaca tratar-se não apenas de "um dos mais dedicados servidores da fotografia brasileira", mas o 
precursor da pesquisa da história da fotografia no Brasil. Na página 72, ele deixa claro a dimensão de sua importância para a preservação da memória e da cultura no Brasil: "Não é, portanto, exagero afirmar que se no Brasil atual a fotografia figura em destaque em prestigiosas coleções públicas, é estudada nas principais universidades, celebrada nas Bienais e nos demais eventos artísticos de grande porte, isto se deve muito ao esforço precursor de Gilberto Ferrez."

No sexto ensaio, Jubiabá de Jorge Amado e o encantamento de três fotógrafos franceses, o autor explica como a publicação de Jubiabá, na França, em 1937 (na França o livro foi lançado com o título de Bahia de tous les saints), atraiu para o Brasil três nomes de primeira grandeza da fotografia: Pierre Verger, Marcel Gautherot e Jean Mazon. A sedutora história do boxeador Antônio Balduíno, principal personagem do livro, e a Bahia sensual e repleta de promessas de felicidade como pano de fundo, seduziram estes, hoje, consagrados nomes da cultura e da fotografia, a trocarem a França pelo Brasil. Qualquer estudioso sabe avaliar o peso desses três nomes para a história da fotografia, principalmente do fotojornalismo (Mazon), antropologia visual (Verger) e arquitetura (Gautherot). Pedro Vasquez desvenda mais esta contribuição de Jorge Amado para a construção da identidade e preservação da memória brasileira.

Um mundo em miniatura: notas sobre a fotografia de arquitetura é o título do sétimo ensaio. Nele, o autor lembra que François Arago, quando anunciou o daguerreótipo para o mundo, em uma reunião conjunta das academias de ciências e artes da França, em 19 de agosto de 1839 (hoje, Dia Mundial da Fotografia), salientou a utilidade da nova invenção para a reprodução de obras de arte e a documentação dos tesouros arquitetônicos da humanidade. Desde então, fotografia e arquitetura vivem uma relação paradoxal de amor e ódio, que o autor explora com sabedoria e bons exemplos.

No oitavo ensaio, sob título Fotojornalismo: antecedentes perspectivas, o autor cumpre o que promete: fala dos aspectos históricos e evolutivos fotojornalismo, de suas primeiras experiências 
na precária imprensa escrita do século XIX aos desafios impostos pela evolução e consolidação da tecnologia digital. De forma organizada e didática, fala do nascimento do fotojornalismo no mundo, de sua chegada e desenvolvimento no Brasil, das grandes revistas ilustradas e jornais diários que valorizaram a fotografia e revolucionaram seu uso na imprensa para, por fim, como todo pesquisador da área, colocar um ponto de interrogação no futuro do fotojornalismo. Na página 117, deixa claro suas dúvidas e preocupações. "A informatização do processo de produção dos jornais e revistas já havia provocado transformações tão amplas e radicais quanto aquelas advindas da introdução da fotografia na imprensa. Agora, o surgimento de uma forma imaterial de imprensa (que não é impressa no sentido literal do termo, como já não era a imprensa falada e televisiva, mas que pertence a um universo distinto do rádio e da televisão) descortina um horizonte virgem e aparentemente infinito para a fotografia e a imagem técnica de forma geral."

Apreensivo com o futuro da imagem, o autor escreve, com sutis doses de bom humor e ironia, seu nono e último ensaio: Zona crepuscular: da fotografia à imagem digital. Neste ensaio, recupera informações da fotografia clássica - ou analógica - e faz pequenas, mas importantes, comparações com a imagem digital - erroneamente chamada por alguns de fotografia digital - e deixa claro: "uma coisa é uma coisa, outra coisa é outra coisa...". Pedro Vasquez reconhece as facilidades e as infindáveis maravilhas da tecnologia digital, mas manifesta preocupações com o futuro da documentação fotográfica frente às constantes inovações tecnológicas que se substituem em curtíssimos espaços de tempo, não raro preterindo ou relegando ao lixo histórico a tecnologia substituída. Neste aspecto, concordo em gênero, número e grau com o autor.

O livro é um deleite para os estudiosos e iniciados em fotografia. Traz muitíssimas informações históricas sobre a fotografia e discussões absolutamente pertinentes neste momento de grandes e enigmáticas transformações. Tudo isso em uma linguagem clara, direta e objetiva. Como 
se diz no jargão acadêmico: o conteúdo é denso e a forma é leve. E mais: Ao final de cada ensaio, o autor indica sites onde o leitor pode se aprofundar ainda mais sobre o assunto abordado e, claro, deliciar-se com centenas de fotografias lá postadas. Da mesma forma que Pedro Afonso Vasquez é referência obrigatória para os que querem aprender, para os que sabem e para os que pensam que sabem fotografia, Fotografia escrita tem tudo para se tornar o livro de cabeceira dos amantes desta arte e fonte de consulta obrigatória para professores e estudantes. 